PAEDIATRIC LUNG DISEASE

\title{
Eosinophil activation and preschool viral wheeze
}

\section{A Oommen, T McNally, J Grigg}

Thorax 2003;58:876-879

Background: A study was undertaken to ascertain whether systemic eosinophil activation is associated with preschool viral wheeze (PVW).

See end of article for authors' affiliations ......................

Correspondence to: Dr J Grigg, Leicester Children's Asthma Centre, Institute for Lung Health, University of Leicester, Leicester LE2 7LX, UK; ig33@le.ac.uk

Revised version received 28 March 2003 Accepted for publication 3 June 2003

Methods: Urinary eosinophil protein X (UEPX) and serum total $\lg E(\lg E)$ levels were measured in children admitted to hospital with PVW, and UEPX was measured 6 weeks after discharge. Two years after admission, current wheeze in children aged $\geqslant 5$ years was determined by questionnaire. Controls were recruited from children undergoing elective surgery (normal controls) and from those with skin prick test reactivity to foods (atopic controls).

Results: There was no difference in uEPX levels between normal controls $(n=15)$ and atopic controls $(n=8)$. uEPX levels were increased in children with acute PVW $(n=84 ; p<0.001 v$ normal controls, $p<0.01 v$ atopic controls) and fell on convalescence $(n=20,95 \% \mathrm{Cl}-217$ to $-31 \mu \mathrm{g} / \mathrm{mmol}$ creatinine, $\mathrm{p}<0.05$ ). In children with acute PVW there was no association between uEPX and serum lgE levels or markers of clinical severity. Respiratory questionnaires were returned for 25/55 eligible children. There was no difference in uEPX level during acute PVW when stratified by "current wheeze" $(n=18)$ or "no wheeze" $(n=7) 2$ years later.

Conclusions: Systemic eosinophil activation is associated with PVW but is not associated with serum $\lg \mathrm{E}$, clinical severity, or persistence of wheeze into the early school age period.

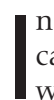
$\mathrm{n}$ preschool children acute exacerbations of wheeze are caused almost exclusively by viral colds (preschool viral wheeze; PVW). ${ }^{12}$ Birth cohort studies suggest that most children with PVW have a phenotype separate from that of classical atopic asthma. For example, the Tucson Children's Respiratory Study found that $60 \%$ of children with PVW were symptom free by 6 years of age, ${ }^{3}$ a "transient" pattern that was not associated with markers of an allergic diathesis such as increased serum IgE. ${ }^{3}$ In contrast, increased serum IgE levels were found in the few children with PVW who continued to wheeze to school age. ${ }^{3}$ From these data we have speculated that the inflammatory substrate in most children with PVW is different from classical atopic asthma. ${ }^{4}$ To date, the degree of overlap between PVW and asthmatic inflammation is unknown, a significant deficiency when targeting anti-inflammatory treatment to preschool children.

Between 1999 and 2002 we performed a trial of parent initiated oral steroids for PVW. Children were recruited when admitted to hospital with acute PVW. A blood sample was obtained to stratify them into two groups based on serum levels of eosinophil cationic protein (ECP) and eosinophil protein $X(E P X)$. Prednisolone or placebo was prescribed to be given for the next episode of PVW. We used the recruitment phase to gain insights into the inflammatory substrate of PVW. To date, we have reported evidence for generalised systemic neutrophil activation in $\mathrm{PVW}^{5}$ (a pattern not usually regarded as critical for asthmatic wheeze) and increased urinary leukotriene E4 in the subgroup with the highest serum IgE levels. ${ }^{6}$

One remaining question is whether eosinophil activation is associated with PVW. Inflammation in atopic asthma is, in part, characterised by increased release of ECP and EPX from pulmonary eosinophils. ${ }^{7}$ Pulmonary eosinophil activation is, in turn, associated with increased serum levels of EPX. ${ }^{8}$ Since serum EPX is excreted unchanged in the urine, urinary $(\mathrm{u})$ EPX levels are increased in atopic asthma and increase further during acute attacks. ${ }^{9}$ 10 In assessing whether eosinophil activation occurs in PVW, urinary markers have an advantage over blood since samples can be taken when symptoms resolve and normal controls are readily available. To date, increased UEPX levels have been reported in a subgroup of acutely wheezy preschool children who were subsequently diagnosed 2 years later with atopic asthma. ${ }^{11}$ However, this study only included children with at least three previous episodes of wheeze, excluded controls with a high probability of atopy, and did not repeat sampling on convalescence. ${ }^{11}$ The relationship between acute wheeze and eosinophil activation for the majority of children with PVW therefore remains unclear.

In the present study we sought evidence for eosinophil activation in children admitted to hospital with PVW. Specifically, we wished to determine whether uEPX levels are raised compared with controls, and whether levels fall on resolution of the wheeze. We hypothesised that UEPX levels in acute PVW would be highest in children with increased serum IgE-that is, in those at increased risk of atopic sensitisation and persistence of wheeze into early school age. ${ }^{3}$

\section{METHODS}

\section{Patients}

Preschool children (1-5 years) with PVW were recruited from those referred by their general practitioner to the admissions unit of the Leicester Royal Infirmary Children's Hospital. Sampling of inflammatory markers in PVW and controls was approved by the ethical committee of the University Hospitals of Leicester NHS trust.

Blood and urine samples from children with acute PVW were obtained if there was a clear symptom history from the parents of a viral cold in the 48 hours preceding the wheeze attack, and physician diagnosed wheeze. Children were excluded if they were premature, had a clinical diagnosis of bacterial infection, and had any other chronic respiratory disease. On admission all children received a single dose of oral prednisolone and nebulised salbutamol as required. Before urine sampling the presence of wheeze and rhinitis was confirmed and a clinical history obtained from the parents. A urine sample was collected within 36 hours of admission for measurement of UEPX, and a simultaneous 
blood sample was obtained for serum IgE and blood eosinophil measurement. The number of nebulised bronchodilators during the admission and the total duration of the illness was recorded from the discharge notes. After discharge the children were visited at home within 6 weeks. If they had no current respiratory symptoms and were potty trained, a urine specimen was collected during the visit (convalescent sample).

"Normal" controls were recruited from a random selection of children undergoing elective ear nose and throat surgery or ophthalmic surgery. None had clinical evidence of active infection and their skin prick reactivity to allergens was unknown. Urine for UEPX measurement was obtained before surgery and a blood sample for serum IgE measurement was obtained soon after induction of anaesthesia.

"Atopic normal" controls were recruited from children with suspected food sensitivity who were attending for food challenge. All had history of a suspected allergic reaction to a food and at least one positive skin prick test to food antigens. Serum IgE measurements were not obtained from atopic controls because of ethical restrictions. Controls with a history of chronic respiratory disease, or previous attacks of wheezing, or symptoms of a respiratory tract infection in the preceding week were excluded.

\section{Follow up}

To establish whether increased uEPX levels during acute PVW were associated with symptoms consistent with a diagnosis of asthma, ${ }^{12}$ parents of children who had (1) a 2 year interval from the original admission and (2) reached 5 or more years of age were sent a respiratory questionnaire. Children of school age were categorised either as having "no wheeze" (in the last 6 months) or "current wheeze" (at least one episode of wheeze in the last 6 months).

\section{Sample collection and analysis}

5-10 ml urine samples were collected using a sterile potty. Urinary infection was excluded using the Multistix 10SG dipstick screening test (Bayer, UK). Urine samples were initially stored in a refrigerator, then aliquoted and transferred to $-70^{\circ} \mathrm{C}$ within 12 hours. The uEPX concentration was measured in unprocessed urine samples using a specific EPX radioimmunoassay kit (Pharmacia, Uppsala, Sweden). Briefly, urine was defrosted at room temperature and $500 \mu \mathrm{l}$ used in the assay. The samples were diluted 11 times in a phosphate buffer containing $0.15 \% \mathrm{NaCl}, 1 \%$ bovine serum albumin, $0.1 \%$ Tween $20,10 \mathrm{nmol} / \mathrm{l}$ EDTA, and $0.2 \%$ $\mathrm{N}$-acetyl-trimethylammonium-bromide as previously described. ${ }^{9}$ The assay was done in duplicate and the mean values were taken. The detection limit of the assay was $<3 \mu \mathrm{g} / \mathrm{l}$, the within assay coefficient of variation was $<5 \%$, and the between assay coefficient of variation was $<10 \%$.
Urinary creatinine was measured by the Jaffe reaction with the Dade Behring dimension analyser (Dade Behring, USA) and uEPX levels were expressed as $\mu \mathrm{g} / \mathrm{mmol}$ creatinine.

For serum IgE, a $2 \mathrm{ml}$ venous blood sample was collected and allowed to clot at room temperature for 60 minutes. Serum was separated by centrifugation before storage at $-20^{\circ} \mathrm{C}$. IgE was measured using the UniCAP Analyser machine (Pharmacia, Sweden) and expressed as kU/l. An absolute eosinophil count was performed on a $0.5 \mathrm{ml}$ heparinised blood sample using routine hospital techniques.

\section{Statistics}

Data are presented as median and interquartile range (IQR). Unpaired data were compared using the Mann-Whitney U test. Paired data were compared using the Wilcoxon signed rank test and expressed as the estimated median difference and $95 \%$ confidence interval (CI). Correlations were determined by Spearman rank correlation $\left(r_{\mathrm{s}}\right)$. Statistical analyses were performed using SPSS for Windows Version 10 (SPSS Inc, Chicago, IL, USA) and Minitab release 13.32 (Minitab Inc, PA, USA). A p value $<0.05$ was considered statistically significant.

\section{RESULTS}

Eighty four children with acute PVW were studied. A convalescent urine sample was obtained from 20 children 6 weeks after discharge. Convalescent samples were not obtained from children who were not fully potty trained or refused to produce a sample during the visit $(n=63)$. One child was excluded because of a readmission with PVW.

Serum IgE levels in the normal controls $(n=15)$ were within the range reported for non-atopic children ${ }^{13}$ (blood was not sampled from atopic controls). Serum IgE levels were increased in children with acute PVW $(\mathrm{n}=73 ; \mathrm{p}<0.01 v$ normal controls, table 1). Blood eosinophil counts in both children with PVW and normal controls were within the normal range but were higher in normal controls $(\mathrm{p}<0.05 v$ acute PVW, table 1). There was no difference in uEPX levels between normal $(\mathrm{n}=15)$ and atopic controls $(\mathrm{n}=8$; table 1 , fig 1). Both control groups were slightly older than the children with PVW (table 1), but there was no association between age and UEPX levels in any group.

uEPX levels were increased during acute PVW $(\mathrm{p}<0.001 v$ normal controls, $\mathrm{p}<0.01 \quad v$ atopic controls, table 1 , fig 1 ). uEPX levels during acute PVW were not associated with (1) serum $\operatorname{IgE}\left(r_{\mathrm{s}}=0.17, \mathrm{p}=\mathrm{NS}\right.$, fig 2$),(2)$ the interval between oral steroid treatment and urine sampling $\left(r_{\mathrm{s}}=0.1, \mathrm{p}=\mathrm{NS}\right.$, fig 3), and (3) the number of salbutamol nebulisations required during the attack $\left(r_{\mathrm{s}}=0.1, \mathrm{p}=\mathrm{NS}\right)$. Furthermore, there was no significant difference in uEPX levels during acute PVW when categorised by family history of atopy (66/ $84)$, previous dry cough or shortness of breath without colds $(n=14 / 84)$, and eczema $(n=27 / 84)$. uEPX levels fell

Table 1 Demographic, serum and urine parameters in children with preschool viral wheeze (PVW) and controls

\begin{tabular}{|c|c|c|c|}
\hline & $\begin{array}{l}\text { PVW } \\
(n=84)\end{array}$ & $\begin{array}{l}\text { Normal controls } \\
(n=15)\end{array}$ & $\begin{array}{l}\text { Atopic controls } \\
(\mathrm{n}=8)\end{array}$ \\
\hline Age (months) & $31(20$ to 41$)$ & $59(41 \text { to } 66)^{* *}$ & $87(58 \text { tol01) })^{\star *}$ \\
\hline uEPX ( $\mu \mathrm{g} / \mathrm{mmol}$ creatinine) & 214 (144 to 383 ) & $82(35 \text { to } 211)^{* *}$ & $84(51 \text { to } 182)^{\star *}$ \\
\hline $\begin{array}{l}\text { Serum total } \lg \mathrm{E} \\
(\mathrm{kU} / \mathrm{l})\end{array}$ & $56(9$ to 209$)(n=73)$ & $12(7 \text { to } 25)^{\star *}$ & Not done \\
\hline $\begin{array}{l}\text { Absolute eosinophil count } \\
\left(\times 10^{9} / \mathrm{I}\right)\end{array}$ & $0.1(0$ to 0.2$)(n=73)$ & $0.25(0.2 \text { to } 0.3)^{*}$ & Not done \\
\hline
\end{tabular}




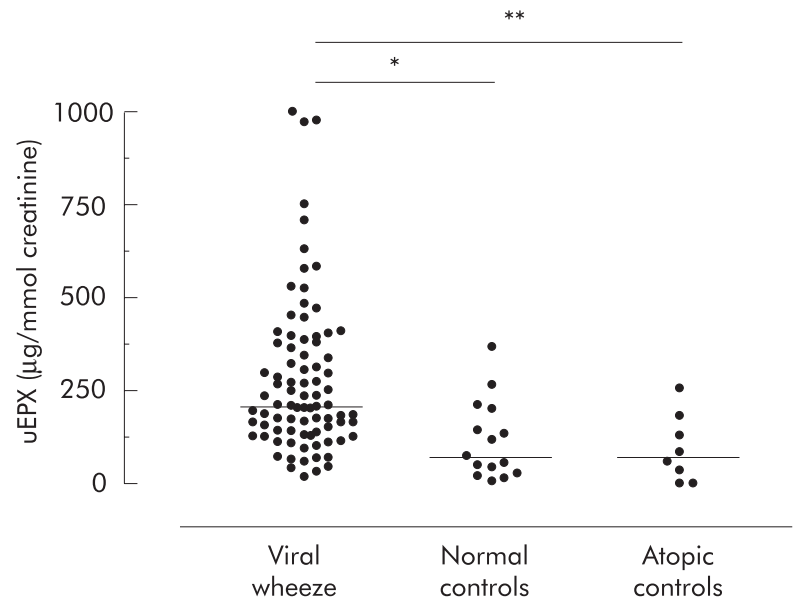

Figure 1 Dotplot of urinary EPX (UEPX) levels in children with acute PVW $(n=84)$, normal controls in whom skin prick reactivity was unknown $(n=15)$, and atopic controls ( $n=8)$. UEPX levels were higher in the children with acute PVW ( ${ }^{*} p<0.001 v$ normal controls; ${ }^{* *} p<0.01 v$ atopic controls, Mann-Whitney U test). Horizontal bars represent medians.

between the acute and convalescent phases of PVW (median $-107 \mu \mathrm{g} / \mathrm{mmol}$ creatinine, $95 \%$ CI -217 to $-31, \mathrm{n}=20$, $p<0.05$, fig 4 ). Convalescent uEPX levels were similar to those of normal- and atopic controls $(p=N S)$. When convalescent UEPX levels were categorised by the presence of eczema (7/20), there was no difference between children with and without eczema, and no difference between children with eczema and normal controls.

Follow up questionnaires were returned for 25 (45\%) of the 55 children who had reached school age in 2003 and who were at least 2 years post admission. Eighteen children continued to have parent reported wheeze in the preceding 6 months (table 2); all had been prescribed inhaled salbutamol, and 11 were receiving regular inhaled steroids. Seven children had no wheeze over the preceding 6 months; none were prescribed inhaled therapy. There was no difference in EPX levels when acute PVW was categorised by the presence or absence of wheeze at the 2 year follow up (table 2).

\section{DISCUSSION}

The main finding of this study is that uEPX levels are increased in acute PVW and fall when wheezing resolves. The large degree of overlap between uEPX levels in acute PVW

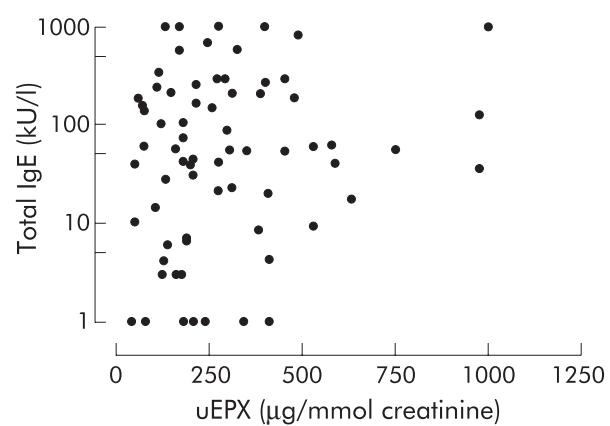

Figure 2 Scatterplot of the association between urinary eosinophil protein $X(U E P X)$ levels and serum lgE levels during acute PVW $\left(r_{\mathrm{s}}=0.17\right.$, $\mathrm{p}=\mathrm{NS})$.

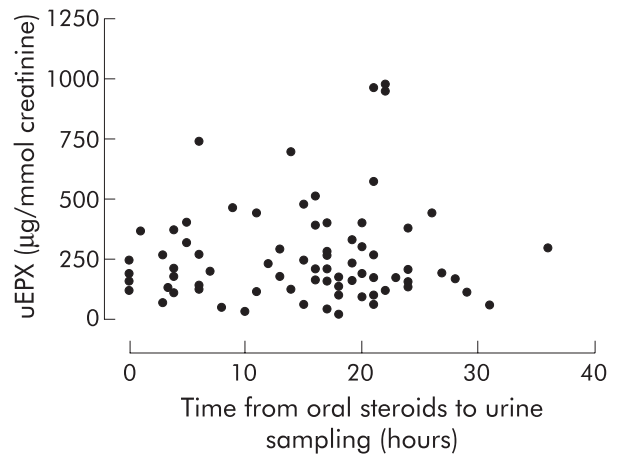

Figure 3 Scatterplot of the association between urinary eosinophil protein $X$ (UEPX) levels during acute PVW and time of urine sample from oral prednisolone therapy $\left(r_{s}=0.1, p=N S\right)$.

and normal controls suggests a marked heterogeneity of eosinophil activation and is compatible with epidemiological studies suggesting that PVW is not a single phenotype. ${ }^{1}$ We originally hypothesised that the highest uEPX levels would occur in children at increased risk of atopic sensitisation. However, no correlation was found between UEPX and serum IgE levels during acute PVW. Other risk factors for eosinophil activation with PVW could not be identified, since no demographic or clinical parameter at the time of admission was associated with increased uEPX levels.

Increased levels of UEPX during PVW did not predict persistence of wheeze into the early school age years. These data would appear to be different from those reported by Øymar ${ }^{11}$ who found increased UEPX in wheezy preschool children who were subsequently diagnosed with atopic asthma. We did not perform skin prick tests at follow up, and an association between acute UEPX and a subsequent diagnosis of "atopic" asthma has not been excluded. However, children who continued to wheeze would be considered as "asthmatic" under the current British Thoracic Society guidelines. ${ }^{12}$ Thus, increased uEPX levels do not signify a "pre-asthmatic" state in our population of children with PVW. Furthermore, the lack of association between IgE and UEPX levels suggests that eosinophil activation in PVW is not initiated by atopic mechanisms. A primary role for the neutrophil in initiating viral wheeze has recently been hypothesised for preschool children. ${ }^{14}$ Indeed, our previous data showing increased neutrophil activation in a separate group of children with $\mathrm{PVW}^{5}$ are compatible with a direct role of neutrophils in initiating systemic eosinophil

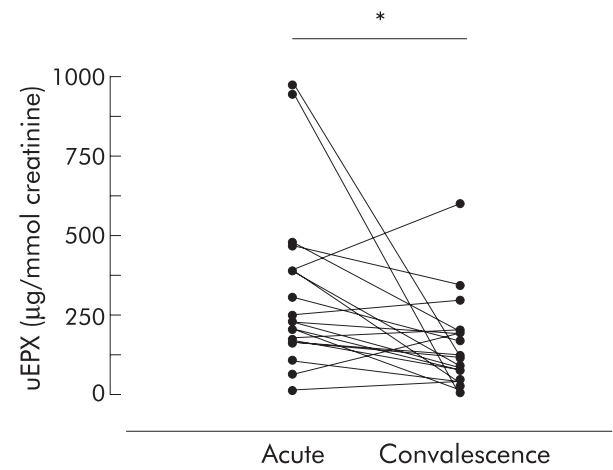

Figure 4 Change in urinary eosinophil protein $X$ (UEPX) levels between the acute and convalescent phase of PVW. ${ }^{*} \mathrm{p}<0.05,95 \% \mathrm{Cl}-217$ to $-31 \mu \mathrm{g} / \mathrm{mmol}$ creatinine, $\mathrm{n}=20$, Wilcoxon signed rank test. 
Table 2 Two year follow up of children with preschool viral wheeze (PVW) who had reached 5 years of age in 2003

Wheeze $(n=18)^{*} \quad$ No wheeze $(n=7)^{*}$

Age at PWW episode

(months)

Age at follow up (months)

37 (31 to 43 )

34 ( 25 to 46 )

lgE during PVW episode

$77(74$ to 86$)$

$83(73$ to 95$)$

(kU/l)

uEPX during PVW episode 245 (166 to 387 ) 310 (203 to 451)

( $\mu \mathrm{g} / \mathrm{mmol}$ creatinine)

Data are presented as median (IQR). There were no differences between the two outcome groups ( $p=N S$, Mann-Whitney $U$ test).

*Parental reported symptoms over the previous 6 months

activation, independent of atopic mechanisms. Further studies are needed which combine markers of neutrophil activation with eosinophil markers in order to elucidate the sequence of inflammatory events in PVW.

Could a confounding factor account for the disassociation between serum IgE and UEPX levels? Corticosteroids downregulate eosinophil activation, ${ }^{15}$ although there is a time lag of several hours between oral steroid therapy and its systemic effects. ${ }^{16}$ All children received a single dose of oral prednisolone on admission, which may therefore have disrupted an association between IgE and uEPX. However, uEPX levels in samples taken within the first hours of admission were no different from those obtained later (fig 3), a pattern that does not indicate therapeutic suppression. Eczema is another potential confounder, since active dermatitis is associated with increased uEPX levels ${ }^{17}$ and a significant minority $(32 \%)$ of children with PVW had mild eczema. However, eczema was not associated with increased uEPX levels, either during the acute or the convalescent phase of PVW.

The normalisation of UEPX on convalescence implies that eosinophil activation in children with PVW is an acute, but not a chronic, phenomenon. Indeed, eosinophil activation was not found in a bronchoalveolar lavage study of children with a history of episodic viral triggered wheeze. ${ }^{18}$ The fall in uEPX levels on convalescence from PVW suggests a role for eosinophils in the pathogenesis of wheeze. However, we have not excluded systemic eosinophil activation with colds per se, although this is unlikely since uEPX levels are not increased in young children with trivial upper respiratory tract illnesses. ${ }^{19}$

In conclusion, we found evidence of eosinophil activation in children with severe acute PVW which normalised with resolution of symptoms. Eosinophil activation in PVW is independent of serum IgE, clinical presentation, and outcome 2 years later. We speculate that eosinophil activation in PVW is not caused by an atopic inflammation but is a result of direct stimulation by non-atopic inflammatory cells.

\section{ACKNOWLEDGEMENTS}

The authors thank Ms Katie Peck for help in recruiting the children. $\mathrm{AO}$ and TM were funded by grant AM2/01/008 from the NHS National R\&D Programme on Asthma Management. JG was funded by the Henry Smith's Charity and Medisearch.

\section{Authors' affiliations}

A Oommen, T McNally, J Grigg, Leicester Children's Asthma Centre, Institute for Lung Health, University of Leicester, PO Box 65, Leicester LE2 7LX, UK

\section{REFERENCES}

1 Weinberger $M$. Consensus statement from a conference on treatment of viral respiratory infection-induced asthma in young children. J Pediatr 2003;142:S45-6.

2 Rylander $E$, Eriksson M, Freyschuss U. Risk factors for occasional and recurrent wheezing after RSV infection in infancy. Acta Paediatr Scand 1988;77:711-5.

3 Taussig LM, Wright AL, Holberg CJ, et al. Tucson Children's Respiratory Study: 1980 to present. J Allergy Clin Immunol 2003;111:661-75.

4 Grigg J, Venge P. Inflammatory markers of outcome. Eur Respir J Suppl 1996;21:16s-21s.

5 Oommen A, Grigg J. Systemic neutrophil activation in acute preschool viralwheeze. Arch Dis Child 2003:88:524-31.

6 Oommen A, Grigg J. Urinary leukotriene E4 in preschool children with acute clinical viral wheeze. Eur Respir J 2003;21:149-54.

7 Lee NA, Gelfand EW, Lee JJ. Pulmonary T cells and eosinophils: coconspirators or independent triggers of allergic respiratory pathology? J Allergy Clin Immunol 2001;107:945-57.

8 Robinson DS, Assoufi B, Durham SR, et al. Eosinophil cationic protein (ECP) and eosinophil protein $X$ (EPX) concentrations in serum and bronchial lavage fluid in asthma. Effect of prednisolone treatment. Clin Exp Allergy 1995;25:1118-27.

9 Koller DY, Halmerbauer G, Frischer T, et al. Assessment of eosinophil granule proteins in various body fluids: is there a relation to clinical variables in childhood asthma? Clin Exp Allergy 1999;29:786-93.

10 Storm van's Gravesande K, Mattes J, Gruntjens T, et al. Circadian variation of urinary eosinophil protein $\mathrm{X}$ in asthmatic and healthy children. Clin Exp Allergy 1999;29:1497-501.

11 \$ymar K. High levels of urinary eosinophil protein $X$ in young asthmatic children predict persistent atopic asthma. Pediatr Allergy Immunol 2001:12:312-7.

12 British Thoracic Society/Scottish Intercollegiate Guidelines Network. British guideline on the management of asthma. Thorax 2003;58(Suppl 1):i1-94.

13 Saarinen UM, Juntunen K, Kajosaari M, et al. Serum immunoglobulin E in atopic and non-atopic children aged 6 months to 5 years. A follow-up study. Acta Paediatr Scand 1982;71:489-94.

14 Cloutier MM. Neutrophils or eosinophils in young children with wheezing: which comes first? Chest 2002;122:761-3.

15 El-Radhi AS, Hogg CL, Bungre JK, et al. Effect of oral glucocorticoid treatment on serum inflammatory markers in acute asthma. Arch Dis Child 2000;83:158-62

16 Jilma B, Voltmann J, Albinni S, et al. Dexamethasone down-regulates the expression of L-selectin on the surface of neutrophils and lymphocytes in humans. Clin Pharmacol Ther 1997;62:562-8.

17 Pucci N, Lombardi E, Novembre E, et al. Urinary eosinophil protein X and serum eosinophil cationic protein in infants and young children with atopic dermatitis: correlation with disease activity. J Allergy Clin Immunol 2000;105:353-7.

18 Stevenson EC, Turner G, Heaney LG, et al. Bronchoalveolar lavage findings suggest two different forms of childhood asthma. Clin Exp Allergy 1997;27:1027-35.

19 Wojnarowski C, Halmerbauer G, Mayatepek E, et al. Urinary leukotriene $E(4)$, eosinophil protein $X$, and nasal eosinophil cationic protein are not associated with respiratory symptoms in 1-year-old children. Allergy $2001 ; 56: 883-8$. 